\title{
Associations between endothelial progenitor cells, clinical characteristics and coronary restenosis in patients undergoing percutaneous coronary artery intervention
}

\author{
Fernando S. Montenegro", Marcelo Correia, Fabiana Muccillo, Christina G. Souza e Silva and Andrea De Lorenzo
}

\begin{abstract}
Objective: Endothelial progenitor cells (EPCS) are produced in the bone marrow and mobilized to the peripheral blood playing a key role in endothelial repair. The objective of this study was to evaluate circulating EPC before and after percutaneous coronary intervention $(\mathrm{PCl})$ with stent implantation and their associations with coronary restenosis and adverse cardiovascular events. Venous blood was obtained before and the day after PCI. Quantification of total white blood count and identification of EPCs $\left(\mathrm{CD} 45^{-} \mathrm{CD} 34^{+} \mathrm{CD} 31^{+} \mathrm{CD} 133 / 2^{+} \mathrm{CD} 309^{+}\right)$through immunophenotyping by flow cytometry was performed. The primary outcome was either restenosis detected by new coronary angiography or angina with myocardial ischemia at the territory of the stented coronary artery. Secondary outcomes were angina without demonstrable myocardial ischemia, acute coronary syndrome or all-cause death.

Results: 37 patients were followed for 1 year. The median EPC count before PCI was 320 cells/mcl and after PCl 286 cells/mcl. A decrease of EPC count was found in $65 \%$ of the patients, while $35 \%$ displayed an increase. Primary outcomes occurred in $10.8 \%$ and the secondary in $37.8 \%$ of the patients. Despite a higher level of EPC before (402 cell/mcl) and after PCl (383 cell/mcl) in patients with the secondary outcomes, there was no significant association between EPC and cardiovascular events.
\end{abstract}

Keywords: Endothelial progenitor cells, Coronary artery disease, Angioplasty, Restenosis, Angina pectoris, Acute coronary syndrome, Percutaneous coronary

\section{Introduction}

Percutaneous coronary intervention (PCI) is currently one of the cornerstones of the treatment of coronary artery disease [1], at least in part due to the lower immediate morbidity and mortality rates in comparison to coronary artery bypass grafting [2]. However, early success may be hampered by restenosis, a reduction of coronary lumen diameter after PCI [3].

Angiographic restenosis is defined as a 50\% narrowing at the PCI site in follow-up angiography, while clinical restenosis is considered present when ischaemic

\footnotetext{
*Correspondence: fernandomonte03@gmail.com
}

Instituto Nacional de Cardiologia, Rua da Laranjeiras, 374-Laranjeiras, Rio de Janeiro 2224006, Brazil symptoms are seen and/or an ischaemic functional test is positive in individuals with $\geq 50 \%$ stenosis of the target vessel [4]. In earlier trials with bare metal stents, angiographic restenosis occurred in up to $1 / 3$ of the procedures [5]. Drug-eluting stents (DES) allowed a reduction in the rates of angiographic restenosis by reducing neointimal hyperplasia; this led to their expanded use in more complex lesions and less selective populations, reelevating the rates of restenosis. A recent study shows an incidence of target-vessel revascularization 1 year after PCI with DES of $7.8 \%$ [6].

Circulating endothelial progenitor cells (EPCs), first described by Asahara et al. [7], are bone marrow-derived cells that express a variety of endothelial surface markers and home to sites of endothelial denudation [8], 
with roles in endothelial repair and angiogenesis [9]. Endothelial damage induced by PCI can mobilize EPCs to the injured areas; the hypothesis is that, after weeks to months, these cells will proliferate and contribute to effective re-endothelization and the restoration of vascular homeostasis [10]. However, other studies have shown conflicting results of whether EPCs exert favourable or unfavourable effects at PCI sites [11]. Since further knowledge of the influence of EPCs on restenosis might help identify patients at higher risk of restenosis or future events [12], this study aimed to evaluate EPC counts before and after PCI and the associations between EPC numbers and both restenosis and clinical outcomes.

\section{Main text \\ Methods}

Male patients $\geq 18$ years with stable angina scheduled for elective PCI with stent implantation at the National Heart Institute in Brazil between January and December 2014 were screened for the present study. Exclusion criteria included the presence of any acute or chronic inflammatory disease, recent surgery or trauma, malignant disease, chronic renal failure undergoing dialysis, acute coronary syndrome $<3$ months, or any complication during PCI or in the $24 \mathrm{~h}$ post-PCI. The study was performed according to the Declaration of Helsinki and was approved by the local ethics committee (Comitê de Ética em Pesquisa do Instituto Nacional de Cardiologia). All participants gave written informed consent. The extent of coronary artery disease was quantified by (1) the number of coronary lesions determining $>50 \%$ obstruction, and (2) the number of coronary arteries with $>50 \%$ lesions. Hypertension was defined as a history of hypertension requiring antihypertensive therapy; a family history of coronary artery disease was defined as the presence of this disease in first-degree relatives (men $<55$ and women $<65$ years of age); diabetes mellitus was defined as the need for oral antidiabetic drug therapy or the use of insulin.

All biochemical analyses and flow cytometry studies were performed by an investigator blinded to patient data and outcomes. This was true for overall data analyses, interpretation and statistical analyses. Only the investigators who were responsible for patient recruitment and follow-up were aware of patient data and outcomes, but these investigators were not involved in the EPC analysis or the overall analysis of the results.

\section{Flow cytometry}

Peripheral venous blood was collected into 4-mL Vacutainer tubes (Becton-Dickinson, Basel, Switzerland) containing liquid tri-potassium ethylene diamine tetra-acetic acid (K3EDTA) immediately before PCI and the next day before hospital discharge (12 $\mathrm{h}$ after the procedure).
Blood samples were refrigerated between $4^{\circ}$ and $8{ }^{\circ} \mathrm{C}$ and processed within $24 \mathrm{~h}$ for total leukocyte count and for EPC isolation. EPCs were quantified by flow cytometry (BD FACSCanto; BD Biosciences, San Jose, CA, USA) and analysed using Infinicyt software (Cytognos, Salamanca, Spain). Briefly, EPCs were identified with phenotypes CD45+/-, CD34+, CD309+ and CD133+. We used a unique labelling and acquisition technique for flow cytometry, but all multiparametric analyses were performed in duplicate. The detailed EPC identification protocol can be found in Additional file 1.

\section{Follow-up and outcomes}

Patients were followed for 1 year, with clinical assessments every 3 months. The primary outcome was defined as the recurrence of typical or atypical angina and evidence of restenosis detected by coronary angiography or by evidence of inducible myocardial ischaemia in the region of the stented coronary artery, demonstrated by stress/rest myocardial perfusion scintigraphy performed according to standard protocols [13]. Secondary outcomes were typical or atypical angina without confirmation of ischaemia by myocardial scintigraphy, the occurrence of acute coronary syndrome (defined by typical symptoms and cardiac biomarkers elevated above the upper limit of normal or new pathological Q waves in at least 2 contiguous electrocardiogram leads) or all-cause death.

\section{Statistical analyses}

We estimated that 34 patients would be needed to provide an $80 \%$ power to detect a difference of 100 cells $/ \mathrm{mcl}$ in the absolute EPC counts before and after PCI, with a standard deviation of $200 \mathrm{cells} / \mathrm{mcl}$ and an alpha level of 0.05 .

Categorical variables are expressed as number and percentage and compared by Fisher's exact test. Continuous variables were tested for normal distributions with the Kolmogorov-Smirnov test, are described as the mean \pm standard deviation or median and interquartile range, and were compared by Student's t test or MannWhitney's test, as appropriate. Correlations were evaluated with Spearman's test. For all analyses, R Commander statistical package was employed (Lucent Technologies, Murray Hill, NY, USA). A P $<0.05$ was considered statistically significant.

\section{Results}

\section{Study population}

Among 53 eligible patients, one was excluded due to post-PCI complications (atrial fibrillation) and 10 due to missing blood samples. Five patients were lost to follow-up, leaving 37 for analysis. The demographic and 
Table 1 Baseline characteristics

\begin{tabular}{ll}
\hline & $\begin{array}{l}\mathbf{n}(\%) \\
\text { or mean } \mathbf{t} \text { standard } \\
\text { deviation }\end{array}$ \\
\hline Age (years) & $65.0 \pm 8.2$ \\
Hypertension & $34(91.9 \%)$ \\
Diabetes & $12(32.4 \%)$ \\
Obesity & $5(13.5 \%)$ \\
Currently smoking & $4(10.8 \%)$ \\
Chronic kidney failure & $3(8.1 \%)$ \\
History of acute coronary syndrome & $19(51.4 \%)$ \\
Prior percutaneous coronary intervention & $12(32.4 \%)$ \\
Prior coronary artery bypass surgery & $2(5.4 \%)$ \\
Medications & \\
Aspirin & $35(94.6 \%)$ \\
Clopidogrel & $25(67.6 \%)$ \\
Angiotensin-converting enzyme inhibitors & $6(16.2 \%)$ \\
Angiotensin receptor blockers & $21(56.8 \%)$ \\
Beta-blocker & $30(81.1 \%)$ \\
Statin & $31(60.8 \%)$ \\
Number of coronary arteries with $\geq 50 \%$ obstruction \\
1
\end{tabular}

clinical characteristics and medications of the patients are listed in Table 1 . Approximately $2 / 3$ had multivessel coronary disease. All patients received at least one stent, most $(83.7 \%)$ in only one coronary artery $(35.1 \%$ in the left anterior descending coronary artery). The remaining $16.3 \%$ received stents in two coronary arteries. Bare-metal stents were placed in $44.2 \%$ of the patients, drug-eluting stents in 23.1 , and $3.8 \%$ received both types of stents.

\section{Endothelial progenitor cells}

The median EPC counts before and after PCI were 320 and 286 cells/mcl, respectively (Fig. 1). Overall, a decrease in EPC count was found in $65 \%$ of the patients, while $35 \%$ showed an increase. The median pre-PCI EPC count, post-PCI EPC count and their difference, according to demographic characteristics and the presence of cardiovascular risk factors, are shown in Additional file 2: Table S1. None of the variables had any significant association with pre-PCI EPC count. There was no correlation between age and EPC count before or after PCI (Additional file 3: Figure S1). Post-PCI EPC counts were significantly associated with beta-blocker use (higher in patients taking beta-blockers). The difference between pre- and post-PCI EPC counts was higher in diabetic patients, who had a larger decrease in EPCs than nondiabetic patients $(\mathrm{P}=0.04)$.

$E P C s$ endothelial progenitor cell

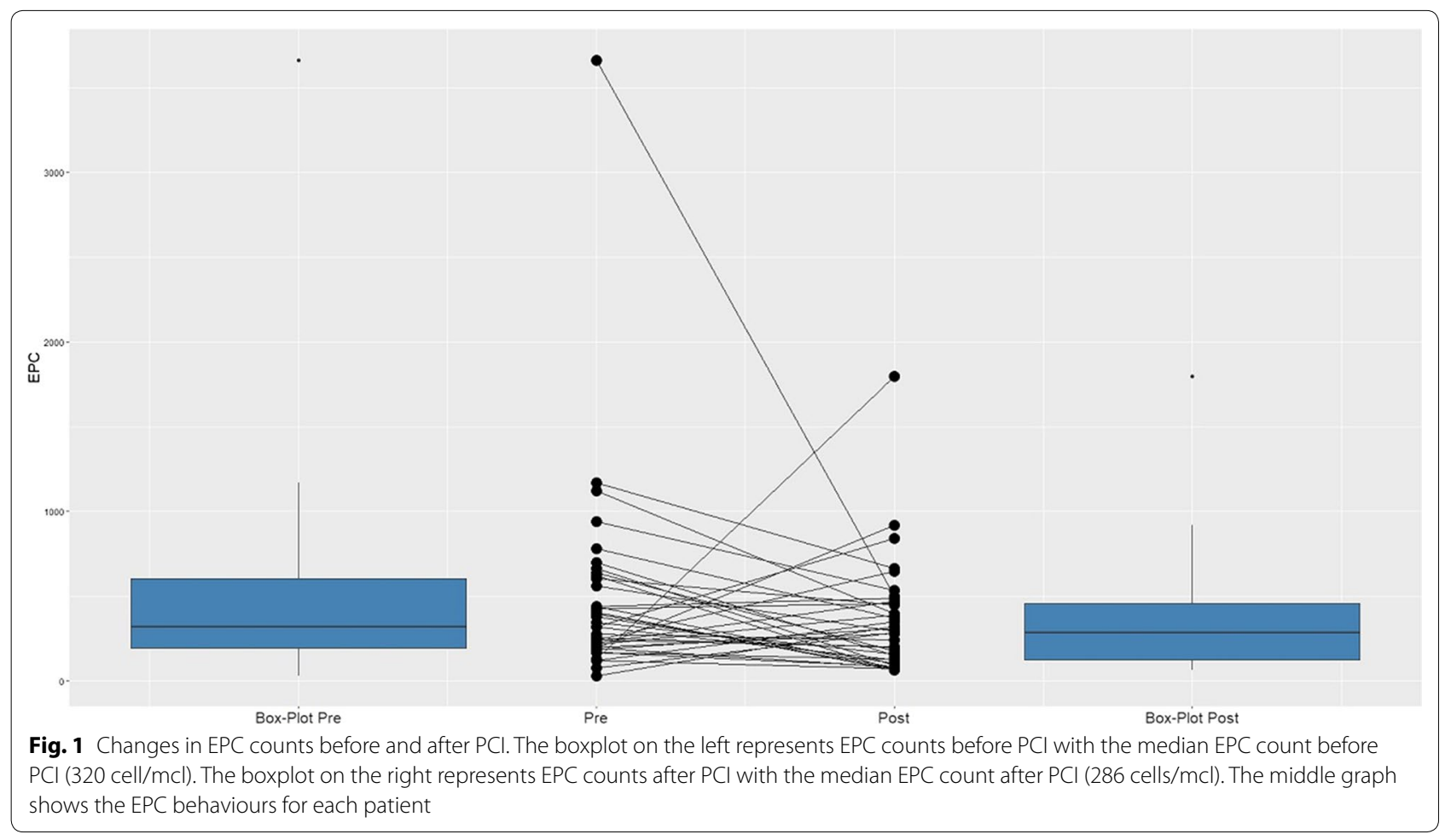




\section{Outcomes and their associations with EPCs}

Eighteen patients $(48.6 \%)$ had one of the outcomes. Four patients (10.8\%) showed primary outcomes; among them, three had restenosis confirmed by coronary angiography, and one had angina and inducible myocardial ischaemia. Secondary outcomes occurred in 14 patients (37.8\%); of these, 10 had angina without evidence of inducible ischaemia, three had acute coronary syndrome, and one patient died due to a subarachnoid haemorrhage (Additional file 4: Figure S2).

Additional file 5: Figure S3 shows absolute the EPC counts in individuals with primary or secondary outcomes. Half of the patients with primary outcomes had an increase in EPC levels after PCI, and half a decrease (Additional file 5: Figure S3: Panel A). In patients with secondary outcomes, $64 \%$ showed an elevation in EPC counts after PCI, and $36 \%$ a reduction in EPC counts (Additional file 5: Figure S3: Panel B). There were no significant differences in EPC counts, pre-PCI, post-PCI or their difference, in patients with any of the outcomes (Table 2), even though the post-PCI medians were higher in patients with secondary outcomes.

\section{Discussion}

Stent placement leads to mechanical injuries that induce substantial local inflammation, stimulating vascular smooth muscle cell proliferation and extracellular matrix depositions, resulting in neointimal thickening and restenosis [14]. After 3 months, complete reendothelization is noted [15].

The role of EPCs in the cardiovascular system and in the pathophysiology of coronary restenosis after PCI is a matter of debate. Although studies describe a protective effect of EPCs in the atherosclerotic process [12], in restenosis, there is a complex relationship between EPCs, endothelial repair and the induction of neointimal proliferation, such that it is still unclear if EPCs have beneficial or detrimental effects in this context [16].

Endothelial progenitor cell count is influenced by age and gender, explained in part by endogenous oestrogen levels $[17,18]$. Therefore, due to the possibility of confounding, we decided to study only men, while being aware that this would limit the generalizability of the results.

Baseline EPC counts were inversely correlated with age and the extent of coronary artery disease (expressed by the number of coronary lesions), similar to that described by Schmidt-Lucke et al. [19].

Diabetic patients had a significant decrease in EPC counts, which parallels prior descriptions of decreased levels and reduced function of EPCs in patients with diabetes [20]. Lee et al. [21] investigated EPC mobilization after elective PCI in diabetic patients, demonstrating an absence of an increase in EPC levels. Similar results were found by Fadini et al. [22], showing EPC cell mobilization impairments in types 1 and 2 diabetics.

Prior studies have also demonstrated the impact of various pharmacological agents on the number and function of EPCs [23]. In this study, post-PCI EPC count was higher in patients taking beta-blockers. This is consistent with the results of Yao et al. [24] when using celiprolol, which increased the number of circulating EPCs and stimulated EPC colony formation and migration while decreasing EPC senescence.

Interestingly, in this study, a decrease in EPC counts after PCI was found in approximately $2 / 3$ of the patients, which is different from other studies that have described increases hypothesized to result from focal EPC mobilizations due to endothelial injuries induced by PCI [25]. These different results can be explained, among other factors, by differences in the subgroups of EPCs studied and by differences in the degree of vascular injury induced by PCI.

Analysing patients who underwent elective PCI, Gao et al. [26] demonstrated different EPC mobilization behaviours in the $24 \mathrm{~h}$ after PCI depending on the degree of vascular injury induced by PCI. On the other hand, Thomas et al. [27] demonstrated a fall in EPC levels $6 \mathrm{~h}$ after the procedure.

Few studies have evaluated the relationship between EPC counts and restenosis or cardiovascular outcomes. In this study there was no significant association between EPC counts and outcomes after PCI. In the study by Pellicia et al. [28], patients with restenosis had higher EPC

Table 2 Comparisons of EPC counts in patients with or without primary or secondary outcomes

\begin{tabular}{|c|c|c|c|c|c|c|}
\hline Outcomes & $\begin{array}{l}\text { EPC count } \\
\text { before PCI (cells/ } \\
\mathrm{mcl} \text { ) }\end{array}$ & $P$ value & $\begin{array}{l}\text { EPC count } \\
\text { after PCI (cells/ } \\
\mathrm{mcl} \text { ) }\end{array}$ & $P$ value & Difference in EPC counts & $P$ value \\
\hline Primary outcome $(n=4)$ & $310(230-442)$ & 0.98 & $412(157-715)$ & 0.46 & $-64(-485-322)$ & 0.50 \\
\hline Without primary outcome $(n=33)$ & $320(192-602)$ & & $285(124-450)$ & & $82(-82-361)$ & \\
\hline Secondary outcome $(n=14)$ & $402(262-654)$ & 0.17 & $383(108-611)$ & 0.34 & $231(-311-521)$ & 0.55 \\
\hline Without secondary outcome $(n=23)$ & $255(189-499]$ & & $280(136-369)$ & & $57(-102-296)$ & \\
\hline
\end{tabular}

Values are the median and interquartile ranges 
counts. However, in contrast to the present study, only bare-metal stents were used, cardiovascular risk factors were less common, and clopidogrel was used for only 1 month, which may explain the different results [28].

The study of EPC is challenging. There are no standard criteria for defining EPC, which may lead to the identification of different subpopulations of EPC [29]. Mobilization and function of EPCs are affected by cardiovascular risk factors, concomitant diseases and the amount of the endothelium that is damaged by PCI, making it difficult to control for all of these influences. Therefore, continued research is necessary to clarify the role of EPC in restenosis and outcomes after PCI, as these cells show promising effects when employed in stents [30].

\section{Limitations}

The major limitation is the small sample size and short follow-up, which makes this a hypothesis-generating study. Additionally, the kinetics of EPC mobilization make it necessary to assess EPC more than one time after PCI. We did not assess the degree of endothelial injury after PCI, which can directly affect mobilization from the bone marrow. Finally, the use of fresh blood samples, longer time interval between pre-PCI and post-PCI, method of EPC measurement and definition of EPC are discussed in Additional file 6.

\section{Additional files}

\section{Additional file 1. EPC identification protocol. \\ Additional file 2: Table S1. EPC counts before PCI, after PCl and their difference.}

Additional file 3: Figure S1. Boxplot figure correlating age with EPC counts before $\mathrm{PCl}$ and after $\mathrm{PCl}$.

Additional file 4: Figure S2. Flowchart depicting patient outcomes.

Additional file 5: Figure S3. Changes in EPC counts before and after PCI.

Additional file 6. Limitations.

\section{Abbreviations}

ACEi: angiotensin converting enzyme inhibitor; ARB: angiotensin receptor blocker; CABG: coronary artery bypass surgery; DES: drug eluting stents; EPC: endothelial progenitor cell; $\mathrm{PCl}$ : percutaneous coronary intervention.

\section{Authors' contributions}

FSM: acquisition of data, interpretation of data, and manuscript drafting; MC: data analysis and statistical interpretation; FM: flow cytometry analysis and critical revision of the manuscript; CG: patient recruitment and initial data analysis; AL: interpretation of data, critical revision of the manuscript and preparation of the final version. All authors read and approved the final manuscript.

\section{Acknowledgements}

The authors thank Dr. Daniel Kasal for useful advice during the analysis of the results.

\section{Competing interests}

The authors declare that they have no competing interests.

\section{Availability of data and materials}

The datasets generated and/or analysed during the current study are available from the corresponding author upon reasonable request.

\section{Consent for publication}

Not applicable.

\section{Ethics approval and consent to participate}

The study received approval from the National Heart Institute Ethics Committee (Number: 662939 dated 29/04/2014). Written informed consent was obtained from all patients included in the study.

\section{Source of funding}

None.

\section{Publisher's Note}

Springer Nature remains neutral with regard to jurisdictional claims in published maps and institutional affiliations.

Received: 7 April 2017 Accepted: 3 May 2018

Published online: 08 May 2018

\section{References}

1. Simonsen M. Changing role for cardiac surgery as use of stents continues growth. Cardiovasc Device Update. 2003;9:1-7.

2. Bangalore S, Guo Y, Samadashvili Z, Blecker S, Xu J, Hannan E. Everolimuseluting stents or bypass surgery for multivessel coronary disease. N Engl J Med. 2015;372:1213-22.

3. Arjomand H, Turi Z, McCormick D, Goldberg S. Percutaneous coronary intervention: historical perspectives, current status, and future direction. Am Heart J. 2003;146(5):787-96.

4. Dangas GD, Claessen BE, Caixeta A, Sanidas EA, Mintz GS, Mehran R. Instent restenosis in the drug-eluting stent era. J Am Coll Cardiol. 2010;56:1897-907.

5. Fischman DL, Leon MB, Baim DS, Schatz RA, Savage MP, Penn I, et al. A randomized comparison of coronary-stent placement and balloon angioplasty in the treatment of coronary artery disease. Stent Restenosis Study Investigators. N Engl J Med. 1994;331:496-501.

6. Misumida N, Aoi S, Saeed M, Ota T, EdaT Umeda H, et al. The role of angiographic follow-up after percutaneous coronary intervention. Int J Cardiol. 2016:222:911-20.

7. Asahara T, Murohara T, Sullivan A, Silver M, van der Zee R, Li T, et al. Isolation of putative progenitor endotelial cells for angiogenesis. Science. 1997;275:964-7.

8. Grant MB, May WS, Caballero S, Brown GA, Guthrie SM, Mames RN, et al. Adult hematopoietic stem cells provide functional hemangioblast activity during retinal neovascularization. Nat Med. 2002;8:607-12.

9. Fadini GP, Losordo D, Dimmeler S. Critical reevaluation of endothelial progenitor cell phenotypes for therapeutic and diagnostic use. Circ Res. 2012;110(4):624-37.

10. Padfield GJ, Newby DE, Mills NL. Understanding the role of endothelial progenitor cells in percutaneous coronary intervention. J Am Coll Cardiol. 2010;55:1553-65

11. Banerjee S, Brilakis E, Zhang S, Roesle M, Lindsey J, Philips B, et al. Endothelial progenitor cell mobilization after percutaneous coronary intervention. Atherosclerosis. 2006;189:70-5.

12. Fadini GP, Maruyama S, Ozaki T, Taguchi A, Meigs J, Dimmeler S, et al. Circulating progenitor cell count for cardiovascular risk stratification: a pooled analysis. PLoS ONE. 2010;5:e11488.

13. Henzlova M, Cerqueira MD, Hansen CL, Taillefer R, Yao SS. ASNC imaging guidelines for nuclear cardiology procedures: stress protocols and tracers. J Nucl Cardiol. 2009. https://doi.org/10.1007/s12350-009-9062-4.

14. Welt FG, Rogers C. Inflammation and restenosis in the stent era. Arterioscler Thromb Vasc Biol. 2002;22:1769-76. 
15. Kipshidze N, Dangas G, Tsapenko M, Moses J, Leon MB, Kutryk M, et al. Role of the endothelium in modulating neointimal formation: vasculoprotective approaches to attenuate restenosis after percutaneous coronary interventions. J Am Coll Cardiol. 2004;44:733-9.

16. Park SJ, Kang SJ, Virmani R, Nakano M, Ueda Y. In-stent neoatherosclerosis: a final common pathway of late stent failure. J Am Coll Cardiol. 2012;59(23):2051-7.

17. Rousseau A, Ayoubi F, Deveaux C, Charbit B, Delmau C, Christin-Maitre $S$, et al. Impact of age and gender interaction on circulating endothelial progenitor cells in healthy subjects. Fertil Steril. 2010;93:843-6.

18. Masuda H, Kalka C, Takahashi T, Yoshida M, Wada M, Kobori M, et al. Estrogen-mediated endothelial progenitor cell biology and kinetics for physiological postnatal vasculogenesis. Circ Res. 2007;101:598-606.

19. Schmidt-Lucke C, Rössig L, Fichtlscherer S, Vasa M, Britten M, Kämper U, Dimmeler S, Zeiher AM. Reduced number of circulating endothelial progenitor cells predicts future cardiovascular events: proof of concept for the clinical importance of endogenous vascular repair. Circulation. 2005;111:2981-7.

20. Tepper OM, Galiano RD, Capla JM, Kalka C, Gagne PJ, Jacobowitz GR, et al. Human endothelial progenitor cells from type II diabetics exhibit impaired proliferation, adhesion an incorporation into vascular structures. Circulation. 2002;106:2781-6.

21. Lee LC, Chen CS, Choong PF, Low A, Tan HC, Poh KK. Time-dependent dynamic mobilization of circulating progenitor cells during percutaneous coronary intervention in diabetics. Int J Cardiol. 2010;142:199-201.

22. Fadini GP, Albiero M, Vigili de Kreutzenberg S, Boscaro E, Cappellari R, Marescotti $M$, et al. Diabetes impairs stem cell and proangiogenic cell mobilization in humans. Diabetes Care. 2013;36:943-9.
23. Antonio N, Fernandes R, Rodriguez-Losada N, Jimenez-Navarro MF, Paiva A, de Teresa Galvan E, et al. Stimulation of endothelial progenitor cells: a new putative effect of several cardiovascular drugs. Eur J Clin Pharmacol. 2010;66:219-30.

24. Yao E-H, Fukuda N, Matsumoto T, Katakawa M, Yamamoto C, Han Y, Ueno $T$, et al. Effects of the antioxidative [beta] blocker celiprolol on endothelial progenitor cells in hypertensive rats. Am J Hypertens. 2008;21:1062-8.

25. Bonello L, Basire A, Sabatier F, Paganelli F, Dignat-George F. Endothelial injury induced by coronary angioplasty triggers mobilization of endothelial progenitor cells in patients with stable coronary artery disease. J Thromb Haemost. 2006;4:979-81.

26. Gao M, Yao Q, Liu Y, Sun F, Ma Y, Sun G, et al. Association between mobilization of circulating endothelial progenitor cells and time or degree of injury from angioplasty in patients with exertional angina: a prospective study. Exp Ther Med. 2015;10(2):809-15.

27. Thomas HE, Avery PJ, Ahmed JM, Edwards R, Purcell I, Zaman AG, et al. Local vessel injury following percutaneous coronary intervention does not promote early mobilisation of endothelial progenitor cells in the absence of myocardial necrosis. Heart. 2009;95:555-8.

28. Pelliccia F, Cianfrocca C, Rosano G, Mercuro G, Speciale G, Pasceri V, et al. Role of endothelial progenitor cells in restenosis and progression of coronary atherosclerosis after percutaneous coronary intervention: a prospective study. JACC Cardiovasc Interv. 2010;3(1):78-86.

29. Leor J, Marber M. Endothelial progenitors: a new tower of Babel? J Am Coll Cardiol. 2006;48:1588-90.

30. Leopold JA. Prohealing endothelial progenitor cell capture stents do the cells captured explain the clinical outcomes? Circ Cardiovasc Interv. 2013;6(5):494-5.
Ready to submit your research? Choose BMC and benefit from:

- fast, convenient online submission

- thorough peer review by experienced researchers in your field

- rapid publication on acceptance

- support for research data, including large and complex data types

- gold Open Access which fosters wider collaboration and increased citations

- maximum visibility for your research: over $100 \mathrm{M}$ website views per year

At BMC, research is always in progress.

Learn more biomedcentral.com/submissions 